\title{
Long-term survival of advanced triple- negative breast cancers with a dose-intense cyclophosphamide/anthracycline neoadjuvant regimen
}

S Giacchetti ${ }^{*, 1}$, R Porcher ${ }^{2}$, J Lehmann-Che ${ }^{3,4}$, A-S Hamy ${ }^{1}$, A de Roquancourt ${ }^{5,6}$, C Cuvier ${ }^{1}$, P-H Cottu ${ }^{1}$,

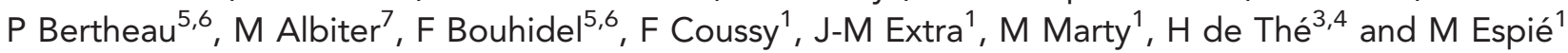
${ }^{1}$ AP-HP, Hôpital Saint-Louis, Breast Disease Unit, University Paris Diderot, Paris 75475, France; ${ }^{2}$ AP-HP, Hôpital Saint-Louis, Biostatistic Department, Paris 75475, France; ${ }^{3}$ AP-HP, Hôpital Saint-Louis, Molecular Biology Department, Paris 75475, France; ${ }^{4}$ INSERM/CNRS/University Paris Diderot UMR 944/7212, Paris 75475, France; ${ }^{5}$ AP-HP, Hôpital Saint-Louis, Pathology Department, Paris 75475, France; ${ }^{6}$ University Paris Diderot, UMR-S-728 INSERM, Paris 75475, France and ${ }^{7}$ AP-HP, Hôpital Saint-Louis, Radiology Department, Paris 75475, France

Background: Triple-negative (TN) breast cancers exhibit major initial responses to neoadjuvant chemotherapy, but generally have a poor outcome. Because of the lack of validated drug targets, chemotherapy remains an important therapeutic tool in these cancers.

Methods: We report the survival of two consecutive series of 267 locally advanced breast cancers (LABC) treated with two different neoadjuvant regimens, either a dose-dense and dose-intense cyclophosphamide-anthracycline (AC) association (historically called SIM) or a conventional sequential association of cyclophosphamide and anthracycline, followed by taxanes (EC-T). We compared pathological responses and survival rates of these two groups and studied their association with tumours features.

Results: Although the two regimens showed equivalent pathological complete response $(p C R)$ in the whole population (16 and $12 \%)$, the SIM regimen yielded a non-statistically higher pCR rate than EC-T (48\% vs $24 \%, P=0.087$ ) in TN tumours. In the SIM protocol, DFS was statistically higher for TN than for non-TN patients $(P=0.019)$, although we showed that the TN status was associated with an increased initial risk of recurrence in both regimens. This effect gradually decreased and after 2 years, TN was associated with a significantly decreased likelihood of relapse in SIM-treated LABC (hazard ratio $(H R)=0.25$ (95\% Cl: 0.07-0.86), $P=0.028)$.

Conclusions: AC dose intensification treatment is associated with a very favourable long-term survival rate in TN breast cancers. These observations call for a prospective assessment of such dose-intense AC-based regimens in locally advanced TN tumours.

Breast cancers represent a set of highly heterogeneous diseases (Weigelt et al, 2008; Sotiriou and Pusztai, 2009). Ongoing studies are pursuing the identification of the cell of origin as well as genetic and epigenetic changes or alterations in signalling pathways associated with each breast cancer subset. Currently, these molecular classifications are not routinely used in clinical practice and breast cancers are still commonly classified according to oestrogen receptor (ER), progesterone receptor (PR) and HER2 status. However, triplenegative (TN) cancer is phenotypically defined by the lack of expression of ERA, PR and the absence of HER2 overexpression and amplification. There are not yet any specifically targeted treatments for this type of breast cancer. Cytotoxic chemotherapy is therefore 
the only treatment in this group that accounts for $\sim 15 \%$ of all breast cancers. Several sets of clinical data show an heterogeneity in TN cancers owing to different molecular alterations and/or supposed cells of origin (basal-like and claudin-low subtypes are the more frequent) (Guedj et al, 2011; Nik-Zainal et al, 2012). Breast cancer subgroups differ very widely in their individual chemotherapy susceptibility, notably through their different rates of tumour cell proliferation (Andre et al, 2005). Until now, breast cancers have derived only small benefits from dose intensification treatment although recent data suggest that some subgroups, including TN tumours, may be very sensitive to dose-dense alkylator-based chemotherapy (Andre and Pusztai, 2006; Gluz et al, 2008; Nieto and Shpall, 2009; Bonilla et al, 2010; Lehmann-Che et al, 2010; Silver et al, 2010; Vollebergh et al, 2011).

Neoadjuvant chemotherapy was initially developed for nonresectable breast cancers, but is now widely used in localised breast cancer not eligible for breast conserving therapy (Rastogi et al, 2008). Such frontline treatment defines pathological complete response (pCR, absence of infiltrating tumour in breast and lymph nodes) as the key endpoint, predicting long-term survival especially in patients with ERA-negative or TN tumours (Liedtke et al, 2008; von Minckwitz et al, 2012b). Several studies have demonstrated that high-grade and ERA-negative tumours achieve higher pCR rates than other subgroups (Guarneri et al, 2006; Caudle et al, 2010; Huober et al, 2010; Jones et al, 2010). Although the benefit of chemotherapy is not restricted to the latter, pCR is, in today's practice,the best mean to identify patients highly responsive to a specific regimen.

We have previously demonstrated that for locally advanced tumours treated with a frontline cyclophosphamide-anthracyclin (AC) dose-dense regimen (Cottu et al, 1999), only tumours with inactivating mutations in the P53 tumour suppressor reached pCR (Bertheau et al, 2002, 2007). Yet, several studies have pointed out that although TN cancers are often initially chemo-sensitive, they usually present an early relapse with a generally poor prognosis (Miller et al, 2005; Foulkes et al, 2010; von Minckwitz et al, 2011). Here, we report the long-term overall survival (OS) of a prospectively followed cohort of patients treated with our dosedense regimen. We then compared our data with those from a companion cohort of patients treated with a conventional taxanecontaining regimen. We observed significant differences in the survival rate of patients with (TN) cancers, urging for the use of AC dose intensification, rather than taxanes, in these subsets.

\section{PATIENTS AND METHODS}

Treatments. From November 1985 to May 2010, 267 patients with locally advanced breast cancer (LABC) were treated at the Saint Louis hospital in the breast disease unit. Patients did not oppose this comparative study, which was approved by the hospital's internal review board. Between 1985 and 2003, patients received six cycles of neoadjuvant dose-dense cyclophosphamide $\left(1.2 \mathrm{~g} \mathrm{~m}^{-2} \mathrm{dl}^{-1}\right)$ and epirubicin $\left(75 \mathrm{mg} \mathrm{m}^{-2} \mathrm{~d}^{-1}\right)$ treatment every 2 weeks (SIM regimen) (Cottu et al, 1999). This neoadjuvant regimen was the local standard of care at the time. After surgery, patients received six cycles of sequential chemotherapy ( 2 courses of FEC 50, 2 cycles of CMF, 2 courses of 5FU, vincristine and methotrexate). Some of these patients were previously reported (Cottu et al, 1999; Bertheau et al, 2002, 2007). For this regimen, the duration of preoperative chemotherapy was 12 weeks, and the overall duration of treatment was 30 weeks. From 2003 to 2010, following the report of taxanes benefit in the neoadjuvant setting (Rastogi et al, 2008), this dose-dense regimen was replaced by a conventional EC- $\mathrm{T}$ regimen (epirubicine $75 \mathrm{mg} \mathrm{m}^{-2} \mathrm{~d}^{-1}$ and cyclophosphamide $750 \mathrm{mg} \mathrm{m}^{-2} \mathrm{~d}^{-1}$ ) every 3 weeks followed by four cycles of docetaxel $100 \mathrm{mgm}^{-2} \mathrm{~d}^{-1}$ every 3 weeks), for a cumulative duration of 24 weeks. No further chemotherapy was administered after surgery. After November 2005, patients with HER2-amplified tumours also received trastuzumab, before and/or after chemotherapy $\left(8 \mathrm{mg} \mathrm{kg}^{-1}\right.$ loading dose, followed by $6 \mathrm{mg} \mathrm{kg}^{-1}$ every 3 weeks for a total 6 or 12 months duration). Endocrine therapy was delivered according to current local practice in the SIM arm. It was thus never delivered if patients had ER-negative tumours, not systematically delivered in case of ER-positive tumours and systematically given if hormone receptors were positive in the EC-T arm. Following chemotherapy completion, patients had either a conservative surgery or a mastectomy, depending on clinical and radiological response. Most patients underwent axillary dissection. All patients in the two cohorts received radiotherapy, after chemotherapy completion and surgery, in the breast and/lymph nodes.

Diagnosis. Breast cancer diagnosis was performed on surgical biopsies between 1985 and 2005 and on core-needle biopsies thereafter. Oestrogen and PR status was determined through the ligand-binding assay from 1990 to 2005 and then by immunohistochemistry (IHC). Whenever possible, the ligand-binding assay was controlled by IHC, IHC being favoured in case of discrepancy. Positivity cutoffs were $10 \mathrm{fmol} \mathrm{mg}^{-1}$ of protein for the biochemistry method, and 10\% staining for IHC. From 2005, HER2 determination was systematically performed by IHC with control by FISH or SISH for ambiguous cases. Retrospective determination of HER2 status was performed whenever possible.

Pathological response. Pathological complete response was defined as the absence of infiltrative carcinoma in the breast and in the lymph nodes. Persistent in situ carcinoma in the breast was considered as a complete response. Patients with involved supraclavicular lymph node were included in the analysis, whereas patients with distant metastatic disease at onset were excluded.

Statistical methods. Results are reported with frequency and per cent for categorical data and median and range for quantitative data. Baseline characteristics were compared between the two regimen groups using Fisher's exact test or the Wilcoxon rank-sum test. Pathological complete response rates were compared using Fisher's exact tests, and interactions with the protocol group were tested using logistic regression models. Disease-free survival (DFS) was counted from the date of biopsy to the date of distant metastases, death or the last follow-up alive with absence of metastases as certained, whichever occurred first. Survival curves were estimated by the Kaplan-Meier product limit estimator and compared using partial likelihood ratio tests in Cox proportional hazards models. The proportional hazards assumption was checked by examination of Schoenfeld residuals and the Grambsch and Therneau lack-of-fit test. When proportional hazards could not be assumed, time-dependent effects were added to the model. Multivariable analysis of DFS was carried out using the Cox model with time-dependent effects, to account for non-proportional hazards. As follow-up was different in the two protocol groups, DFS was censored at 84 months in all analyses involving comparison between SIM and EC-T protocols. Models were adjusted on usual prognostic factors, that is, tumour size, HER2 status, histological grade and nodal status. Although we decided not to conform to the 'rule of thumb' of 10 events per variable (Vittinghoff and McCulloch, 2007), we kept the number of predictors as low as possible. Interactions between biological parameters and the treatment protocol were tested. Given the overlaps between ER status and TN status, both were not entered together in the model. It was decided on clinical grounds to use a TN status. All tests were two-sided and $P$-values $\leqslant 0.05$ were considered as indicating significant association. Analyses were performed using R 2.10.1 statistical software. 


\section{RESULTS}

Two hundred and sixty-seven patients with LABCs were treated in our breast disease unit. Ninety-nine patients were treated with SIM, whereas 168 patients received EC-T chemotherapy regimen. Median follow-up time from initiation of chemotherapy was 127 months for patients in the SIM arm (range 23-248) and 52 months for patients in the EC-T arm (range 10-97). Baseline patients and tumour features showed significantly more frequent T4 size and high histological grade in patients treated with the SIM protocol (Table 1a). Triplenegative tumours represented $23 \%$ and $25 \%$ of cases, respectively (Table 1b). Pathological response was assessed in all patients who underwent surgery (100\% in SIM and $98 \%$ in EC-T). This doseintensive anthracycline-based regimen was manageable in regards of toxicity despite pronounced myelotoxicity (Cottu et al, 1999).

Pathological complete response in the whole and TN population. Similar global rates of pCR were observed in the two patient

\begin{tabular}{|c|c|c|c|}
\hline Variable & SIM & EC-T & $P$-value \\
\hline No. patients & 99 & 168 & \\
\hline Age, median (range), years & $46(24-76)$ & $48(26-78)$ & 0.046 \\
\hline Clinical tumour & & & 0.004 \\
\hline $\begin{array}{l}\text { T1 } \\
\text { T2 } \\
\text { T3 } \\
\text { T4 }\end{array}$ & $\begin{array}{c}0(0) \\
16(16) \\
51(52) \\
32(32)\end{array}$ & $\begin{array}{c}2(1) \\
50(30) \\
88(52) \\
28(17)\end{array}$ & \\
\hline Clinical nodal status & & & 0.12 \\
\hline $\begin{array}{l}\text { N0 } \\
\text { N1 } \\
\text { N2 } \\
\text { N3 }\end{array}$ & $\begin{array}{c}23(23) \\
53(54) \\
21(21) \\
2(2)\end{array}$ & $\begin{array}{c}57(34) \\
87(52) \\
21(12) \\
3(2)\end{array}$ & \\
\hline Histological type & & & 0.65 \\
\hline $\begin{array}{l}\text { Ductal } \\
\text { Lobular } \\
\text { Other }\end{array}$ & $\begin{array}{c}91(92) \\
6(6) \\
2(2)\end{array}$ & $\begin{array}{c}148(88) \\
14(8) \\
6(4)\end{array}$ & \\
\hline Histological grade & & & 0.007 \\
\hline $\begin{array}{l}\text { Grade } 1 \\
\text { Grade } 2 \\
\text { Grade } 3 \\
\text { Missing }\end{array}$ & $\begin{array}{c}0(0) \\
49(50) \\
49(50) \\
1\end{array}$ & $\begin{array}{c}13(8) \\
82(49) \\
71(43) \\
2\end{array}$ & \\
\hline ER expression & & & $>0.99$ \\
\hline $\begin{array}{l}\text { Negative } \\
\text { Positive } \\
\text { Missing }\end{array}$ & $\begin{array}{c}31(34) \\
61(66) \\
7\end{array}$ & $\begin{array}{c}56(33) \\
112(67) \\
0\end{array}$ & \\
\hline $\begin{array}{l}\text { PR expression } \\
\text { Negative } \\
\text { Positive } \\
\text { Missing }\end{array}$ & $\begin{array}{c}48(53) \\
43(47) \\
8\end{array}$ & $\begin{array}{c}106(63) \\
61(37) \\
1\end{array}$ & 0.11 \\
\hline HER2 expression & & & 0.62 \\
\hline $\begin{array}{l}\text { Negative } \\
\text { Positive } \\
\text { Missing }\end{array}$ & $\begin{array}{c}72(79) \\
19(21) \\
8\end{array}$ & $\begin{array}{c}137(82) \\
30(18) \\
1\end{array}$ & \\
\hline Triple negative & & & 0.76 \\
\hline $\begin{array}{l}\text { No } \\
\text { Yes } \\
\text { Missing }\end{array}$ & $\begin{array}{c}70(77) \\
21(23) \\
8\end{array}$ & $\begin{array}{c}125(75) \\
42(25) \\
1\end{array}$ & \\
\hline \multicolumn{4}{|c|}{$\begin{array}{l}\text { Abbreviations: } E R=\text { oestrogen receptor; HER2 = human epidermal growth factor receptor } 2 \text {; } \\
P R=\text { progesterone receptor; pts = patients. }\end{array}$} \\
\hline
\end{tabular}

groups, $16 \%(16 / 99)$ and $12 \%(19 / 165)$ in SIM and EC-T, respectively (Table 2). This was associated with an identical 7-year-DFS rate of 59\% (95\% CI: 50-69\%) for SIM vs 60\% (48-76\%) for EC-T (Figure 1B) and same OS rate of 74\% (95\% CI: $65-83 \%$ ) for SIM vs 71\% (59-86\%) for EC-T (Figure 1A).

We first studied the predictive factors for pathological pCR. It was assessed in 99 patients (100\%) in the SIM group and 165 (98\%) in the EC-T group (Table 2). HER2 overexpression had no influence on pCR in both protocol groups. ER-negative tumours were more likely to achieve pCR than ER-positive tumours, both in SIM (14 out of 31 patients (45\%) vs 2 out of 61 (3\%)) and, to a lesser extent, in EC-T (13 out of 55 (24\%) vs 6 out of $110(5 \%)$ ). Interaction between ER-negative tumour patients and the type of protocol (SIM vs EC-T) reached borderline significance, with a $P$-value of 0.099 . Similarly, TN tumours were associated with nonstatistically significantly higher pCR rates, than non-TN tumours in both SIM (10 out of 21 (48\%) vs 6 out of $70(9 \%))$ and to a lesser extent in EC-T (10 out of 41 (24\%) vs 9 out of 123 (3.7\%)), although interaction between response in TN tumours and the type of protocol was negative $(P=0.27)$.

Disease-free survival and $O S$ in TN patients. We analysed the DFS of patients with TN tumours and with non-TN tumours in both protocols (Figure 2; Supplementary Figure). In the SIM protocol, DFS was significantly longer for TN patients than for non-TN ones $(P=0.019)$ (Figure $2 \mathrm{~A})$, whereas in the EC-T protocol, the DFS was almost significantly shorter $(P=0.066)$ (Figure 2B; Supplementary Figure A and B). Patients with TN tumours exhibited a DFS plateau, with a stable $76 \%$ DFS at 7 years in the SIM, whereas DFS of EC-T-treated patients decreased up to $57 \%$ at 7 years.

In the SIM protocol, the OS rate at 7 years was the same for patients with TN tumours as for patients with non-TN tumours,

Table 1b. Patients with triple-negative tumour characteristics at inclusion (\%)

\begin{tabular}{|c|c|c|c|c|}
\hline Variable & SIM-TN & $\begin{array}{c}\text { SIM-non } \\
\text { TN }\end{array}$ & EC-T-TN & $\begin{array}{c}\text { EC-T-non } \\
\text { TN }\end{array}$ \\
\hline No. patients & 21 & 70 & 42 & 125 \\
\hline $\begin{array}{l}\text { Age, median } \\
\text { (range), years }\end{array}$ & $46(29-69)$ & $46(24-76)$ & 47 (29-78) & $49(26-76)$ \\
\hline \multicolumn{5}{|c|}{ Clinical tumour } \\
\hline $\begin{array}{l}\text { T1 } \\
\text { T2 } \\
\text { T3 } \\
\text { T4 }\end{array}$ & $\begin{array}{c}0(0) \\
4(19) \\
15(71) \\
2(10)\end{array}$ & $\begin{array}{c}0(0) \\
8(11) \\
34(49) \\
28(40)\end{array}$ & $\begin{array}{c}0(0) \\
14(33) \\
24(57) \\
4(10)\end{array}$ & $\begin{array}{c}2(2) \\
36(29) \\
63(50) \\
24(19)\end{array}$ \\
\hline \multicolumn{5}{|c|}{ Clinical nodal status } \\
\hline $\begin{array}{l}\text { N0 } \\
\text { N1 } \\
\text { N2 }\end{array}$ & $\begin{array}{r}7(33) \\
11(52) \\
3(14)\end{array}$ & $\begin{array}{l}16(23) \\
39(56) \\
13(19)\end{array}$ & $\begin{array}{r}14(33) \\
21(50) \\
6(14)\end{array}$ & $\begin{array}{l}43(34) \\
66(53) \\
14(11)\end{array}$ \\
\hline \multicolumn{5}{|c|}{ Histological type } \\
\hline $\begin{array}{l}\text { Ductal } \\
\text { Lobular } \\
\text { Other }\end{array}$ & $\begin{array}{c}20(95) \\
0(0) \\
1(5)\end{array}$ & $\begin{array}{c}63(90) \\
6(9) \\
1(1)\end{array}$ & $\begin{array}{c}36(86) \\
1(2) \\
5(12)\end{array}$ & $\begin{array}{c}111(89) \\
13(10) \\
1(1)\end{array}$ \\
\hline \multicolumn{5}{|c|}{ Histological grade } \\
\hline $\begin{array}{l}\text { Grade } 1 \\
\text { Grade } 2 \\
\text { Grade } 3 \\
\text { Missing }\end{array}$ & $\begin{array}{c}0(0) \\
3(14) \\
18(86) \\
0\end{array}$ & $\begin{array}{c}0(0) \\
40(57) \\
30(43) \\
0\end{array}$ & $\begin{array}{c}0(0) \\
8(19) \\
34(81) \\
0\end{array}$ & $\begin{array}{c}12(10) \\
74(60) \\
37(30) \\
2\end{array}$ \\
\hline
\end{tabular}

Abbreviation: $\mathrm{TN}=$ triple negative. 
respectively $76 \%$ and $71 \%, P=0.78$. Conversely, in the EC-T protocol, the OS at 7 years was worse for patients with TN tumours than for patients with non-TN tumours, respectively $65 \%$ vs $75 \%$, $P=0.001$ (Figure 2C and D; Supplementary Figure C and D).

Multivariate analysis. To account for confounding factors that might have biased the comparison of these two regimens, we performed a multivariable analysis of DFS and OS incorporating common prognostic factors parameters (tumour size, nodal status, HER2 overexpression, histological grade, hormonal receptors,

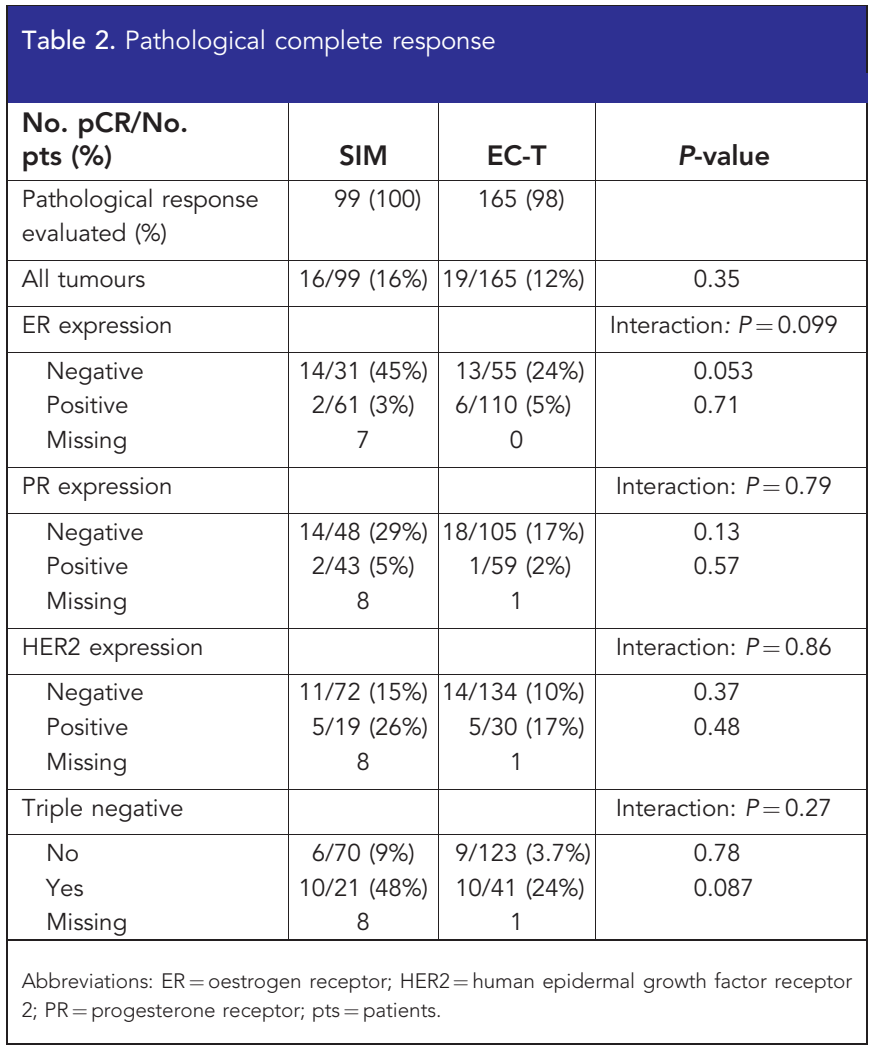

Table 3). Node invasion was associated with a twofold increase in relapse risk and death $(P=0.002$ and $P=0.006$, respectively), whereas tumour size, histological grade and HER2 expression were not significantly associated with relapse or death. There was a strong interaction between TN status and treatment $(P=0.023)$, with a non-constant effect in time for TN $v s$ non TN both for DFS $(P<0.004)$ and OS $(P=0.0004)$. Overall, TN status was associated with an increased initial risk of recurrence that gradually decreased $(P=0.004)$ as well as a hazard ratio (HR) of 2.33 (95\% CI $(1.21-$ $4.49)$ ) during the first 24 months of follow-up until 0.16 (95\% CI (0.02-1.21)) after 48 months of follow-up.

Using the non-TN patients treated with EC-T as the standard, there is a fourfold $(\mathrm{HR}=3.98,95 \% \mathrm{CI}(1.69-9.37))$ increase in relapse risk in the first 2 years in TN patients treated with EC-T $(P=0.002)$ compared with the non-TN ones (Table 3$)$. Non-TN patients treated by SIM had a higher, although non-significant, risk of relapse than those treated by EC-T before 2 years $(\mathrm{HR}=2.09$, $95 \%$ CI $(0.93-4.68), P=0.075)$. TN patients treated with SIM had a significantly lower risk of recurrence after 2 years compared with those treated with EC-T $(\mathrm{HR}=0.25,95 \%$ CI $(0.07-0.86)$, $P=0.028)$. Similar results were observed for OS, although the difference between SIM and EC-T was not significant (Table 3).

\section{DISCUSSION}

This retrospective analysis of patients from a single institution treated with two distinct neoadjuvant regimens yielded unexpected and impressive results that may provide important clues for TN breast cancer chemotherapy. We demonstrate that dose intensification is a major independent variable in the outcome of TN LABC. Therefore, these observations suggest that the SIM regimen is better suited than EC-T for TN LABC.

Despite the higher prevalence of poor prognostic factors in the SIM-treated group, and the fact that 23 EC-T-treated patients received trastuzumab theoretically favouring the EC-T group, pCR and 7-year survival rates were similar in both populations. As in most other neoadjuvant studies (Nieto and Shpall, 2009; Silver et al, 2010), both SIM and EC-T preferentially triggered pCR

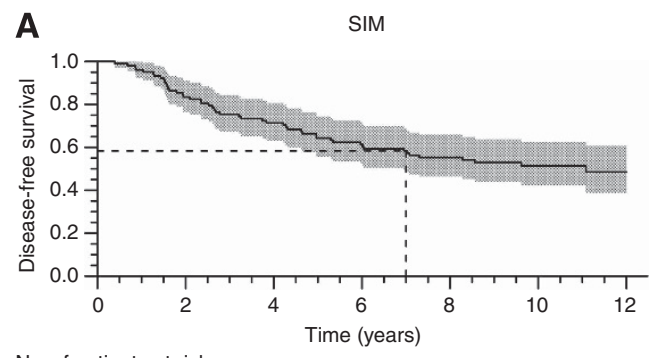

No. of patients at risk
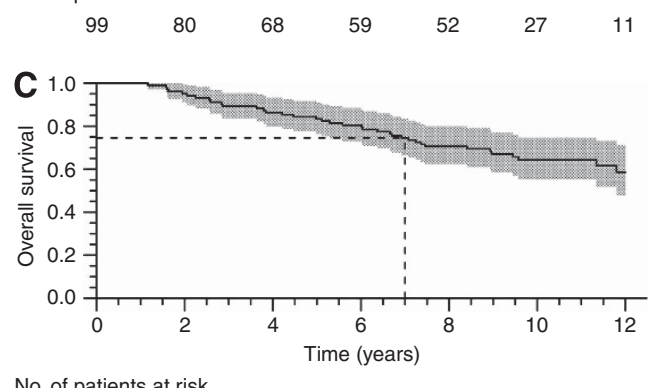

No. of patients at risk

$99 \quad 93$

$\begin{array}{lllll}84 & 78 & 67 & 38 & 19\end{array}$

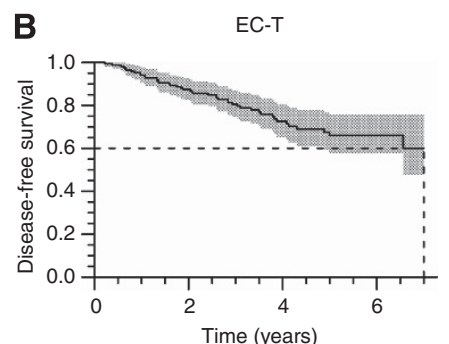

No. of patients at risk

$\begin{array}{llll}168 & 139 & 62 & 19\end{array}$

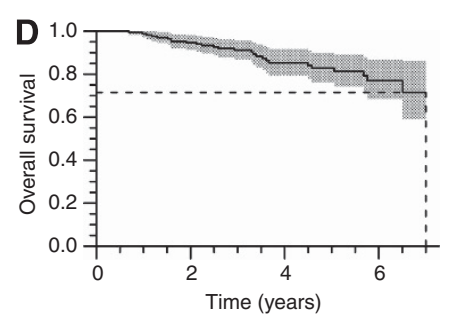

No. of patients at risk

$\begin{array}{llll}168 & 151 & 75 & 24\end{array}$

Figure 1. Overall survival and disease-free survival of the patients treated with SIM (A and $\mathbf{C})$ and EC-T (B and $\mathbf{D})$. Numbers of patients still followed at each time point are indicated. Time is in years, shaded areas represent pointwise $95 \%$ confidence intervals. 

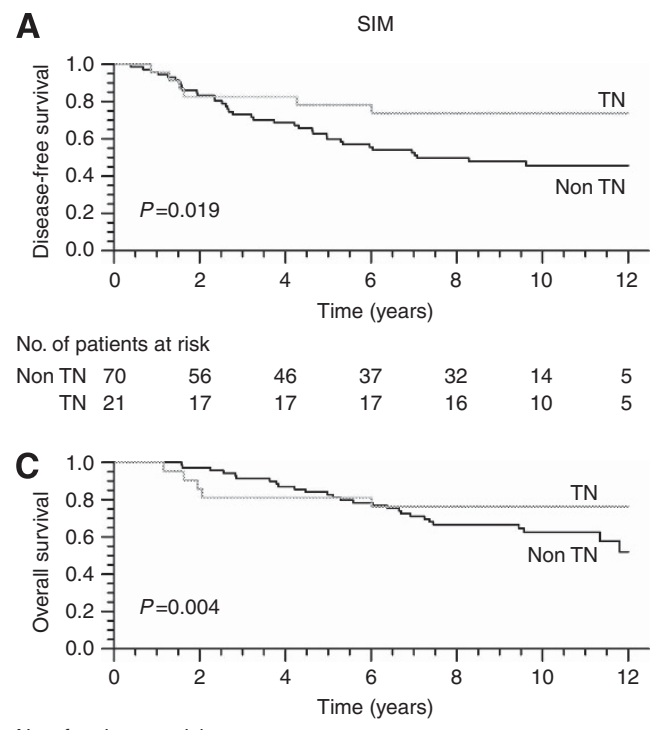

No. of patients at risk

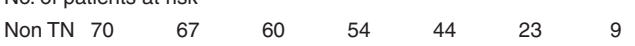
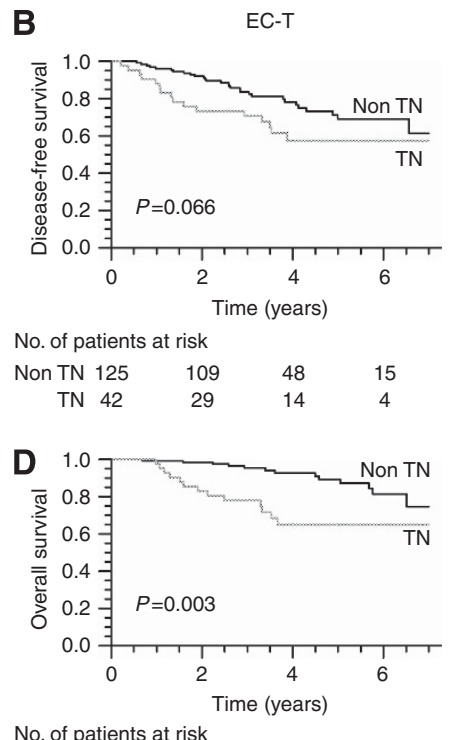

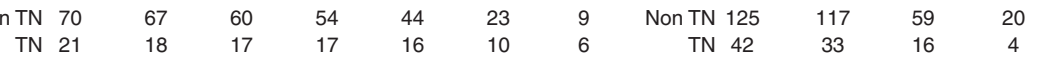

Figure 2. Disease-free survival (A, B) and OS (C, D) of patients with TN and non-TN LABC tumours in the SIM (A, C) and in the EC-T (B, D). Restricting the analysis to the first 72 months, the SIM regimen achieved a significantly longer DFS than EC-T in patients with TN tumours.

Table 3. Results of multivariable analysis of DFS and OS

\begin{tabular}{|c|c|c|c|c|}
\hline \multirow[b]{2}{*}{ Variable } & \multicolumn{2}{|c|}{ DFS } & \multicolumn{2}{|c|}{ OS } \\
\hline & HR $(95 \% \mathrm{Cl})$ & $P$-value & $\mathrm{HR}(95 \% \mathrm{Cl})$ & $P$-value \\
\hline Histological grade 3 & $1.00(0.61-1.65)$ & 0.98 & $1.39(0.73-2.64)$ & 0.31 \\
\hline$N$-stage $\geqslant 2$ & $2.19(1.33-3.60)$ & 0.002 & $2.35(1.28-4.33)$ & 0.006 \\
\hline T-stage 4 & $1.10(0.66-1.85)$ & 0.71 & $1.41(0.73-2.72)$ & 0.31 \\
\hline TN status by protocol interaction & & 0.023 & & 0.063 \\
\hline Non-constant effect in time for TN & & 0.004 & & 0.0004 \\
\hline \multicolumn{5}{|l|}{ TN vs non-TN with EC-T } \\
\hline $\begin{array}{l}\text { Before } 2 \text { years } \\
\text { After } 2 \text { years }\end{array}$ & $\begin{array}{l}3.98(1.69-9.37) \\
0.74(0.28-1.95)\end{array}$ & $\begin{array}{l}0.002 \\
0.54\end{array}$ & $\begin{array}{l}12.4(2.94-52.2) \\
1.42(0.51-3.94)\end{array}$ & $\begin{array}{l}0.0006 \\
0.50\end{array}$ \\
\hline \multicolumn{5}{|l|}{ SIM vs EC-T in non TN } \\
\hline $\begin{array}{l}\text { Before } 2 \text { years } \\
\text { After } 2 \text { years }\end{array}$ & $\begin{array}{l}2.09(0.93-4.68) \\
0.95(0.49-1.81)\end{array}$ & $\begin{array}{l}0.075 \\
0.87\end{array}$ & $\begin{array}{l}2.06(0.46-9.16) \\
1.02(0.47-2.22)\end{array}$ & $\begin{array}{l}0.34 \\
0.95\end{array}$ \\
\hline \multicolumn{5}{|l|}{ SIM vs EC-T in TN } \\
\hline $\begin{array}{l}\text { Before } 2 \text { years } \\
\text { After } 2 \text { years }\end{array}$ & $\begin{array}{l}0.55(0.20-1.56) \\
0.25(0.07-0.86)\end{array}$ & $\begin{array}{l}0.26 \\
0.028\end{array}$ & $\begin{array}{l}0.66(0.19-2.29) \\
0.33(0.09-1.24)\end{array}$ & $\begin{array}{l}0.52 \\
0.10\end{array}$ \\
\hline
\end{tabular}

in high-grade ER-negative tumours and pCR was very strongly associated with long-term survival (data not shown). Indeed, the SIM regimen was significantly more potent in yielding $\mathrm{PCR}$ and long-term DFS rate in TN tumours (Tables 2 and 3; Figure 2A and C; Supplementary Figure A and C). On the contrary, in ER-positive patients, the heterogeneity of endocrine treatment between the two regimens did not allow strong conclusions on survival to be drawn. In TN tumours, the adjusted survival analysis shows a difference between the two treatments.

The key observation from this study is the presence of a longterm survival plateau of $70-80 \%$ for $\mathrm{TN}$ advanced tumours. Importantly in our study, whereas only $48 \%$ of patients with TN
LABC tumours reached pCR (Table 3), 75\% experienced longterm survival (Figure 2C; Supplementary Figure C), suggesting that surgery eradicated the remaining tumours burden. Mechanistically, the SIM regimen is thought to be a very potent inducer of DNA double-strand breaks, by cross-linking the two DNA strands.

Although we know that TNBC has always been associated with higher response rate than non-TN tumours, we still do not know what is the optimal chemotherapy. It has long been suspected that some breast cancers may be very sensitive to dose-intense alkylating agent-containing protocols (Nieto and Shpall, 2009; Silver et al, 2010; Vollebergh et al, 2011). 
Currently, for TN tumours it is recommended to use the same chemotherapy regimen as for non-TN disease, mostly a 3-week regimen of an anthracyclin-cyclophophamide combination followed by docetaxel. However, the use of anthracyclins is still controversial in TNBC. In a combined analysis of two International Breast Cancer Study Groups (IBCSG, Trials VIII and IX), CMF regimen was shown to be likely equal to or better than FEC (Colleoni et al, 2010). On the contrary, Huober, from the German Gepar group, showed a pCR of $39 \%$ in 509 patients with TNBC treated with TAC or TAC-NX (docetaxel/doxorubicin/cyclophosphamide/vinorelbine/capecitabine), which represents the highest pCR rate reported in a large multicenter phase III trial (Huober et al, 2010; Oakman et al, 2010). Patients with TN tumours also benefit from taxanes as reported in the Gepartrio study mentioned above (Hayes et al, 2007; Huober et al, 2010). The efficacy of docetaxel was assessed in a recent metaanalysis in early breast cancers. Benefit in DFS was seen across all subgroups, including TN status ones (Jacquin et al, 2012). Small studies have suggested that platinum may be particularly effective for TNBC based on the histopathological similarities between $\mathrm{TN}$ breast cancers and BRCA1-mutated breast cancers (Foulkes et al, 2010). Cells with BCRA1 mutations are deficient in DNA repair mechanisms, which makes them sensitive to platinum agents. For example, pCR rate as high as $54.6 \%$ was reported in TNBC treated with a combination of docetaxel and carboplatin (Chang et al, 2010), 40\% in another study combining epirubicin, cisplatin, fluorouracil followed by weekly paclitaxel (Torrisi et al, 2008) and $80 \%$ in a BRCA1mutated population (Byrski et al, 2010). However, these data are based on small studies and need further validation in large randomised studies, specially for non-BRCA-related TNBC. Because of the high level of intratumoral VEGF in TN tumours (Linderholm et al, 2009), it was suggested that VEGF inhibitors might be well suited for TN breast cancers. Unfortunately, two large phase III trials reported conflicting results. In the study run by the German group (von Minckwitz et al, 2012a, b), the addition of bevacuzimab to neoadjuvant chemotherapy significantly increased the pCR specifically in the TN breast cancer subgroup. In the NSABP-B40 study, which assessed the impact of bevacuzimab combined with neoadjuvant chemotherapy (Bear et al, 2012), the subgroup analysis revealed a more pronounced effect of bevacuzimab on hormonal receptor-positive tumours. Because of the discrepancy in these results, bevacizumab is not recommended in TNBC treated in neoaadjuvant setting.

A better understanding of TN tumour biology had led to identification of potential new targets as poly-ADP ribose polymerase (PARP) inhibitors (Fong et al, 2009; Tutt et al, 2010; O'Shaughnessy et al, 2011). In tumours with BRCA1 or BRCA2 mutations (most of which are TN) (Manie et al, 2009), inhibition of PARP further compromises DNA repair leading to cell death (Andre and Pusztai, 2006; Lehmann-Che et al, 2010; Vollebergh et al, 2011). A lot of TNBC are basal-like molecular subtypes and they share similarities with BRCA1-associated breast cancer as deficiency in DNA repair pathways. Iniparib was purported to be a PARP inhibitor that showed promised results in a phase II study in patients with metastatic TN breast cancers. The phase III trial failed to show differences in PFS as well as OS. Recent data suggest that iniparib is not only structurally different from other PARP inhibitors but is also a poor inhibitor of PARP activity (Mateo et al, 2013).

Triple-negative tumours belong to a molecularly heterogeneous group of tumours with different molecular alterations, future studies should aim at elucidating more refined biomarkers implicated such as TP53 mutation, BRCA1 status, basal status, CGH profile (Arnedos et al, 2012).

Our data suggest that the initial response of TN tumours to the SIM regimen is followed by long-term survival and most likely definitive cures. In summary, this long-term survival analysis bears implications for the management of TN breast cancers and calls for prospective trials using this dose-dense cyclophosphamideanthracyclin combination.

\section{ACKNOWLEDGEMENTS}

We thank all the patients who participated in these studies, as well as the dedicated staff at our Breast Cancer Unit, and from the Pathology and Molecular Biology Departments, St Louis University hospital, Paris. This study was supported by grants from LNCC.

\section{REFERENCES}

Andre F, Khalil A, Slimane K, Massard C, Mathieu MC, Vignot S, Assi H, Delaloge S, Spielmann M (2005) Mitotic index and benefit of adjuvant anthracycline-based chemotherapy in patients with early breast cancer. J Clin Oncol 23: 2996-3000.

Andre F, Pusztai L (2006) Molecular classification of breast cancer: implications for selection of adjuvant chemotherapy. Nat Clin Pract Oncol 3: $621-632$.

Arnedos M, Bihan C, Delaloge S, Andre F (2012) Triple-negative breast cancer: are we making headway at least? Ther Adv Med Oncol 4: 195-210.

Bear HD, Tang G, Rastogi P, Geyer Jr. CE, Robidoux A, Atkins JN, Baez-Diaz L, Brufsky AM, Mehta RS, Fehrenbacher L, Young JA, Senecal FM, Gaur R, Margolese RG, Adams PT, Gross HM, Costantino JP, Swain SM, Mamounas EP, Wolmark N (2012) Bevacizumab added to neoadjuvant chemotherapy for breast cancer. $N$ Engl J Med 366: 310-320.

Bertheau P, Plassa F, Espie M, Turpin E, de Roquancourt A, Marty M, Lerebours F, Beuzard Y, Janin A, de The H (2002) Effect of mutated TP53 on response of advanced breast cancers to high-dose chemotherapy. Lancet 360: 852-854.

Bertheau P, Turpin E, Rickman DS, Espie M, de Reynies A, Feugeas JP, Plassa LF, Soliman H, Varna M, de Roquancourt A, Lehmann-Che J, Beuzard Y, Marty M, Misset JL, Janin A, de The H (2007) Exquisite sensitivity of TP53 mutant and basal breast cancers to a dose-dense epirubicincyclophosphamide regimen. PLoS Med 4: e90.

Bonilla L, Ben-Aharon I, Vidal L, Gafter-Gvili A, Leibovici L, Stemmer SM (2010) Dose-dense chemotherapy in nonmetastatic breast cancer: a systematic review and meta-analysis of randomized controlled trials. J Natl Cancer Inst 102: 1845-1854.

Byrski T, Gronwald J, Huzarski T, Grzybowska E, Budryk M, Stawicka M, Mierzwa T, Szwiec M, Wisniowski R, Siolek M, Dent R, Lubinski J, Narod S (2010) Pathologic complete response rates in young women with BRCA1-positive breast cancers after neoadjuvant chemotherapy. J Clin Oncol 28: 375-379.

Caudle AS, Gonzalez-Angulo AM, Hunt KK, Liu P, Pusztai L, Symmans WF, Kuerer HM, Mittendorf EA, Hortobagyi GN, Meric-Bernstam F (2010) Predictors of tumor progression during neoadjuvant chemotherapy in breast cancer. J Clin Oncol 28: 1821-1828.

Chang HR, Glaspy J, Allison MA, Kass FC, Elashoff R, Chung DU, Gornbein J (2010) Differential response of triple-negative breast cancer to a docetaxel and carboplatin-based neoadjuvant treatment. Cancer 116: 4227-4237.

Colleoni M, Cole BF, Viale G, Regan MM, Price KN, Maiorano E, Mastropasqua MG, Crivellari D, Gelber RD, Goldhirsch A, Coates AS, Gusterson BA (2010) Classical cyclophosphamide, methotrexate, and fluorouracil chemotherapy is more effective in triple-negative, node-negative breast cancer: results from two randomized trials of adjuvant chemoendocrine therapy for node-negative breast cancer. J Clin Oncol 28: 2966-2973.

Cottu PH, Zelek L, Extra JM, Espie M, Mignot L, Morvan F, Marty M (1999) High-dose epirubicin and cyclophosphamide every two weeks as first-line chemotherapy for relapsing metastatic breast cancer patients. Ann Oncol 10: 795-801.

Fong PC, Boss DS, Yap TA, Tutt A, Wu P, Mergui-Roelvink M, Mortimer P, Swaisland H, Lau A, O'Connor MJ, Ashworth A, Carmichael J, Kaye SB, Schellens JH, de Bono JS (2009) Inhibition of poly(ADP-ribose) polymerase in tumors from BRCA mutation carriers. N Engl J Med 361: 123-134.

Foulkes WD, Smith IE, Reis-Filho JS (2010) Triple-negative breast cancer. $N$ Engl J Med 363: 1938-1948. 
Gluz O, Nitz UA, Harbeck N, Ting E, Kates R, Herr A, Lindemann W, Jackisch C, Berdel WE, Kirchner H, Metzner B, Werner F, Schutt G, Frick M, Poremba C, Diallo-Danebrock R, Mohrmann S (2008) Triple-negative highrisk breast cancer derives particular benefit from dose intensification of adjuvant chemotherapy: results of WSG AM-01 trial. Ann Oncol 19: 861-870.

Guarneri V, Broglio K, Kau SW, Cristofanilli M, Buzdar AU, Valero V, Buchholz T, Meric F, Middleton L, Hortobagyi GN, Gonzalez-Angulo AM (2006) Prognostic value of pathologic complete response after primary chemotherapy in relation to hormone receptor status and other factors. J Clin Oncol 24: 1037-1044.

Guedj M, Marisa L, de Reynies A, Orsetti B, Schiappa R, Bibeau F, MacGrogan G, Lerebours F, Finetti P, Longy M, Bertheau P, Bertrand F, Bonnet F, Martin AL, Feugeas JP, Bieche I, Lehmann-Che J, Lidereau R, Birnbaum D, Bertucci F, de The H, Theillet C (2011) A refined molecular taxonomy of breast cancer. Oncogene 31: 1196-1206.

Hayes DF, Thor AD, Dressler LG, Weaver D, Edgerton S, Cowan D, Broadwater G, Goldstein LJ, Martino S, Ingle JN, Henderson IC, Norton L, Winer EP, Hudis CA, Ellis MJ, Berry DA (2007) HER2 and response to paclitaxel in node-positive breast cancer. N Engl J Med 357: 1496-1506.

Huober J, von Minckwitz G, Denkert C, Tesch H, Weiss E, Zahm DM, Belau A, Khandan F, Hauschild M, Thomssen C, Hogel B, Darb-Esfahani S, Mehta K, Loibl S (2010) Effect of neoadjuvant anthracycline-taxane-based chemotherapy in different biological breast cancer phenotypes: overall results from the GeparTrio study. Breast Cancer Res Treat 124: 133-140.

Jacquin JP, Jones S, Magne N, Chapelle C, Ellis P, Janni W, Mavroudis D, Martin M, Laporte S (2012) Docetaxel-containing adjuvant chemotherapy in patients with early stage breast cancer. Consistency of effect independent of nodal and biomarker status: a meta-analysis of 14 randomized clinical trials. Breast Cancer Res Treat 134: 903-913.

Jones RL, Salter J, A'Hern R, Nerurkar A, Parton M, Reis-Filho JS, Smith IE, Dowsett M (2010) Relationship between oestrogen receptor status and proliferation in predicting response and long-term outcome to neoadjuvant chemotherapy for breast cancer. Breast Cancer Res Treat 119: 315-323.

Lehmann-Che J, Andre F, Desmedt C, Mazouni C, Giacchetti S, Turpin E, Espie M, Plassa LF, Marty M, Bertheau P, Sotiriou C, Piccart M, Symmans WF, Pusztai L, de The H (2010) Cyclophosphamide dose intensification may circumvent anthracycline resistance of p53 mutant breast cancers. Oncologist 15: $246-252$.

Liedtke C, Mazouni C, Hess KR, André F, Tordai A, Mejia JA, Symmans WF, Gonzalez-Angulo AM, Hennessy B, Green M, Cristofanilli M, Hortobagyi GN Pusztai L (2008) Response to neoadjuvant therapy and long-term survival in patients with triple-negative breast cancer. J Clin Oncol 26(8): 1275-1281.

Linderholm BK, Hellborg H, Johansson U, Elmberger G, Skoog L, Lehtio J, Lewensohn R (2009) Significantly higher levels of vascular endothelial growth factor (VEGF) and shorter survival times for patients with primary operable triple-negative breast cancer. Ann Oncol 20: 1639-1646.

Manie E, Vincent-Salomon A, Lehmann-Che J, Pierron G, Turpin E, Warcoin M, Gruel N, Lebigot I, Sastre-Garau X, Lidereau R, Remenieras A, Feunteun J, Delattre O, de The H, Stoppa-Lyonnet D, Stern MH (2009) High frequency of TP53 mutation in BRCA1 and sporadic basal-like carcinomas but not in BRCA1 luminal breast tumors. Cancer Res 69: 663-671.

Mateo J, Ong M, Tan DS, Gonzalez MA, de Bono JS (2013) Appraising iniparib, the PARP inhibitor that never was-what must we learn? Nat Rev Clin Oncol 10: 688-696.

Miller LD, Smeds J, George J, Vega VB, Vergara L, Ploner A, Pawitan Y, Hall P, Klaar S, Liu ET, Bergh J (2005) An expression signature for p53 status in human breast cancer predicts mutation status, transcriptional effects, and patient survival. Proc Natl Acad Sci USA 102: 13550-13555.

Nieto Y, Shpall EJ (2009) High-dose chemotherapy for high-risk primary and metastatic breast cancer: is another look warranted? Curr Opin Oncol 21: $150-157$.

Nik-Zainal S, Van Loo P, Wedge DC, Alexandrov LB, Greenman CD, Lau KW, Raine K, Jones D, Marshall J, Ramakrishna M, Shlien A, Cooke SL, Hinton J, Menzies A, Stebbings LA, Leroy C, Jia M, Rance R, Mudie LJ, Gamble SJ, Stephens PJ, McLaren S, Tarpey PS, Papaemmanuil E, Davies HR, Varela I, McBride DJ, Bignell GR, Leung K, Butler AP, Teague JW, Martin S, Jonsson G, Mariani O, Boyault S, Miron P, Fatima A, Langerod A, Aparicio SA, Tutt A, Sieuwerts AM, Borg A, Thomas G, Salomon AV, Richardson AL, Borresen-Dale AL, Futreal PA, Stratton MR, Campbell PJ (2012) The life history of 21 breast cancers. Cell 149: 994-1007.
O'Shaughnessy J, Osborne C, Pippen JE, Yoffe M, Patt D, Rocha C, Koo IC, Sherman BM, Bradley C (2011) Iniparib plus chemotherapy in metastatic triple-negative breast cancer. N Engl J Med 364: 205-214.

Oakman C, Viale G, Di Leo A (2010) Management of triple negative breast cancer. Breast 19: 312-321.

Rastogi P, Anderson SJ, Bear HD, Geyer CE, Kahlenberg MS, Robidoux A, Margolese RG, Hoehn JL, Vogel VG, Dakhil SR, Tamkus D, King KM, Pajon ER, Wright MJ, Robert J, Paik S, Mamounas EP, Wolmark N (2008) Preoperative chemotherapy: updates of National Surgical Adjuvant Breast and Bowel Project Protocols B-18 and B-27. J Clin Oncol 26: 778-785.

Silver DP, Richardson AL, Eklund AC, Wang ZC, Szallasi Z, Li Q, Juul N, Leong CO, Calogrias D, Buraimoh A, Fatima A, Gelman RS, Ryan PD, Tung NM, De Nicolo A, Ganesan S, Miron A, Colin C, Sgroi DC, Ellisen LW, Winer EP, Garber JE (2010) Efficacy of neoadjuvant cisplatin in triple-negative breast cancer. J Clin Oncol 28: 1145-1153.

Sotiriou C, Pusztai L (2009) Gene-expression signatures in breast cancer. $N$ Engl J Med 360: 790-800.

Torrisi R, Balduzzi A, Ghisini R, Rocca A, Bottiglieri L, Giovanardi F, Veronesi P, Luini A, Orlando L, Viale G, Goldhirsch A, Colleoni M (2008) Tailored preoperative treatment of locally advanced triple negative (hormone receptor negative and HER2 negative) breast cancer with epirubicin, cisplatin, and infusional fluorouracil followed by weekly paclitaxel. Cancer Chemother Pharmacol 62: 667-672.

Tutt A, Robson M, Garber JE, Domchek SM, Audeh MW, Weitzel JN, Friedlander M, Arun B, Loman N, Schmutzler RK, Wardley A, Mitchell G, Earl H, Wickens M, Carmichael J (2010) Oral poly(ADP-ribose) polymerase inhibitor olaparib in patients with BRCA1 or BRCA2 mutations and advanced breast cancer: a proof-of-concept trial. Lancet 376: 235-244.

Vittinghoff E, McCulloch CE (2007) Relaxing the rule of ten events per variable in logistic and Cox regression. Am J Epidemiol 165: 710-718.

Vollebergh MA, Lips EH, Nederlof PM, Wessels LF, Schmidt MK, van Beers EH, Cornelissen S, Holtkamp M, Froklage FE, de Vries EG, Schrama JG, Wesseling J, van de Vijver MJ, van Tinteren H, de Bruin M, Hauptmann M, Rodenhuis S, Linn SC (2011) An aCGH classifier derived from BRCA1mutated breast cancer and benefit of high-dose platinum-based chemotherapy in HER2-negative breast cancer patients. Ann Oncol 22: 1561-1570.

von Minckwitz G, Eidtmann H, Rezai M, Fasching PA, Tesch H, Eggemann H, Schrader I, Kittel K, Hanusch C, Kreienberg R, Solbach C, Gerber B, Jackisch C, Kunz G, Blohmer JU, Huober J, Hauschild M, Fehm T, Muller BM, Denkert C, Loibl S, Nekljudova V, Untch M (2012a) Neoadjuvant chemotherapy and bevacizumab for HER2-negative breast cancer. N Engl J Med 366: 299-309.

von Minckwitz G, Untch M, Blohmer JU, Costa SD, Eidtmann H, Fasching PA, Gerber B, Eiermann W, Hilfrich J, Huober J, Jackisch C, Kaufmann M, Konecny GE, Denkert C, Nekljudova V, Mehta K, Loibl S (2012b) Definition and impact of pathologic complete response on prognosis after neoadjuvant chemotherapy in various intrinsic breast cancer subtypes. J Clin Oncol 30: 1796-1804.

von Minckwitz G, Untch M, Nuesch E, Loibl S, Kaufmann M, Kummel S, Fasching PA, Eiermann W, Blohmer JU, Costa SD, Mehta K, Hilfrich J, Jackisch C, Gerber B, du Bois A, Huober J, Hanusch C, Konecny G, Fett W, Stickeler E, Harbeck N, Muller V, Juni P (2011) Impact of treatment characteristics on response of different breast cancer phenotypes: pooled analysis of the German neo-adjuvant chemotherapy trials. Breast Cancer Res Treat 125: 145-156.

Weigelt B, Horlings HM, Kreike B, Hayes MM, Hauptmann M, Wessels LF, de Jong D, Van de Vijver MJ, Van't Veer LJ, Peterse JL (2008) Refinement of breast cancer classification by molecular characterization of histological special types. J Pathol 216: 141-150.

This work is published under the standard license to publish agreement. After 12 months the work will become freely available and the license terms will switch to a Creative Commons AttributionNonCommercial-Share Alike 3.0 Unported License. 